\title{
Expression of carbohydrate antigens in the rat uterus during early pregnancy and after ovariectomy and steroid replacement
}

\author{
S. J. Kimber ${ }^{1}$, I. M. Illingworth ${ }^{1}$ and S. R. Glasser ${ }^{2}$ \\ ${ }^{1}$ School of Biological Sciences, University of Manchester, Stopford Building, Oxford Road, Manchester, \\ M13 9PT, UK; and ' Department of Cell Biology, Baylor College of Medicine, One Baylor Plaza, \\ Houston, TX 77030, USA
}

\begin{abstract}
Monoclonal antibodies were used to examine the expression of a number of carbohydrate antigens in the rat endometrial epithelium from day 1 to day 8 of pregnancy and in ovariectomized rats supplemented with ovarian steroids. Carbohydrate antigens based on the Gal $\beta I-G l c N A c$ backbone structure were expressed and some of these $\left(\mathrm{Le}^{\mathrm{y}}, \mathrm{Le}^{\mathrm{x}}, \mathrm{B}\right.$ antigen) were present at all stages of pregnancy and independent of ovarian steroids. The $\mathrm{H}$-type- 2 antigen was stimulated by progesterone and expressed in the sensitized and receptive uterus, but was not detected after implantation or, in ovariectomized rats, in the refractory phase. The H-type-I antigen, which is stimulated by oestrogen in the mouse, appeared to be stimulated by progesterone in rats. It was expressed throughout the period of pregnancy but maximal expression was found on days 4-5. The histo-blood group A antigen appeared in ovariectomized rats only after treatment with progesterone followed by three daily injections of progesterone and oestrogen, and in the corresponding postimplantation period of pregnant rats. Its appearance corresponded to the loss of detectable H-type-2 antigen. This study shows that the rat endometrial epithelium expresses some carbohydrate antigens not expressed in mice ( $A$ and $B$ antigen) or under completely different steroidal regulation (H-type- 1 ). Moreover, the $T$ antigen was expressed on the endometrial epithelium adjacent to decidua on days 7 and 8 of pregnancy, but not in rats given ovarian steroids to mimic the sensitized, receptive or refractory phase. Differences in expression between glandular and luminal epithelia indicated differences in steroidal regulation, as found in mice.
\end{abstract}

\section{Introduction}

In vivo, blastocysts can attach only to uteri that have undergone maturational changes induced by an appropriate sequence of ovarian steroids (Finn and Martin, 1970; Psychoyos, 1973). In rodents, increased titres of ovarian progesterone convert the uterus to a sensitized organ that, when subjected to a small transitory increase in nidatory oestrogen between day 3 and day 4 of pregnancy (McCormack and Greenwald, 1974; Watson et al., 1975), becomes receptive to embryo attachment (Psychoyos, 1973; Glasser and McCormack, 1979a; Glasser 1990). Neither RNA nor protein synthesis is required for receptivity (Finn and Bredl, 1973). Indeed, nidatory oestrogen suppresses RNA initiation sites (Glasser and McCormack, 1979b). The receptive period (window of implantation; Psychoyos, 1986) appears to last about $24 \mathrm{~h}$ in rodents, after which the uterus will no longer support blastocyst attachment (refractory period; Psychoyos, 1973, 1986).

However, attachment in vitro to extrauterine sites takes place regardless of the hormonal environment (Colwell, 1969; Enders

Received 18 May 1994. et al., 1981). These data suggest that, under certain conditions, functional and structural changes occur at the apical surfaces of the uterine epithelial cells that allow attachment, and the luminal epithelium becomes receptive. Under different conditions, the uterine epithelial cells either fail to produce adhesion molecules or produce ligands that prevent attachment (Glasser, 1990; Mulholland and Glasser, 1991).

Until recently little was known about the identity of molecules specifically involved in blastocyst implantation. Molecular markers for the sensitized, receptive and refractory uterus have not been available. Consistent changes are documented, such as the thinning of the glycocalyx around the time of implantation (receptive period) in rodents and rabbits (Enders and Schlafke, 1974; Chavez and Anderson, 1985) and the parallel decrease in surface charge (Hewitt et al., 1979; Morris and Potter, 1984; Anderson and Hoffman, 1984; Jansen et al., 1985). Changes in the expression of apical cell surface carbohydrate epitopes during the peri-implantation period are indicated by alterations in the binding of certain lectins (Chavez and Anderson, 1985).

Our knowledge of the differential effects of ovarian steroids on the synthesis, assembly, and secretion of apparently stagespecific uterine epithelial glycoproteins is becoming more 
Table 1. Regimen for steroid treatment of ovariectomized rats

Days

Group (treatment begins 10 days after ovariectomy)
Physiological status of rat uterus

\begin{tabular}{|c|c|c|c|c|c|c|c|c|c|c|c|}
\hline b & $\mathrm{O}$ & $\mathrm{O}$ & - & - & $\mathrm{O}$ & $\mathrm{O}$ & $\mathrm{O}$ & K & & & Oestrogen control \\
\hline$d$ & $\mathrm{O}$ & $\mathrm{O}$ & 一 & - & $\mathrm{P}$ & $\mathrm{P}$ & $P+o$ & K & & & Receptive \\
\hline e & $\mathrm{O}$ & $\mathrm{O}$ & - & - & $\mathrm{P}$ & $\mathrm{P}$ & $P+o$ & $P+o$ & $P+o$ & $\mathrm{~K}$ & Refractory \\
\hline
\end{tabular}

O: primary dose of $100 \mathrm{ng}$ oestradiol.

o: nidatory dose of $50 \mathrm{ng}$ oestradiol.

P: 5 mg progesterone.

$\mathrm{K}$ : day rats killed.

detailed. Oestrogen stimulates sugar metabolism and glycosylation in the uterus, preferentially stimulating branched $\mathrm{N}$-linked lactosaminoglycans in the murine uterus (Dutt et al., 1986; Carson et al., 1987). Synthesis of a number of endometrial proteins and glycoproteins is increased by oestrogen (Kuivanen and De Sombre, 1985; Teng et al., 1986; Anderson et al., 1986; Brown et al., 1990). While progesterone decreases cell surface glycosylation and expression of specific glycoproteins (Anderson and Hoffman, 1984; Mulholland and Leroy, 1989; Svalander et al., 1990; Brown et al., 1990), it stimulates the expression of other glycoproteins (Anderson et al., 1986; Mulholland and Leroy, 1989; Svalander et al., 1990). Investigators have had difficulty in resolving the interplay between these two steroids on the expression of molecules by endometrial epithelial cells and with identifying specific roles for particular molecules in implantation.

There is increasing interest in the role of carbohydrates in cell-cell adhesion in mammalian reproductive processes. They have been implicated in fertilization (Wassarman, 1990) and compaction of the early embryo (Kimber, 1988; Fenderson et al., 1990). The role of the selectin family of carbohydrate binding molecules has been defined in the initial adhesion of leucocytes to endothelial cells at sites of inflammation, and in lymphocyte homing (Lasky, 1992; Bevilacqua and Nelson, 1993). The possibility of a carbohydrate-selectin-like interaction has been suggested to explain the specific carbohydrate sensitivity of mouse embryo attachment to endometrial epithelial cells (Kimber et al., 1993, 1994). The purified oligosaccharide lacto- $N$-fucopentanose 1 , carrying the histo-blood group H-type-I antigen at its nonreducing terminal, blocks blastocyst attachment to endometrial epithelial monolayers in vitro (Lindenberg et al., 1988). Synthesis of the H-type-1 antigen in mouse endometrial epithelium is stimulated by oestrogen (Kimber and Lindenberg, 1990; Kimber et al., 1994; White and Kimber, 1994) and exhibits a marked change in expression around the peri-implantation period. Expression becomes low or negligible after implantation. It follows that endometrial carbohydrates carrying H-type- 1 may be involved in initial adhesion of the mouse embryo (Lindenberg et al, 1988; Kimber et al., 1993, 1994). The H-type-1 epitope is also expressed on the endometrial epithelium of other species (for example, cows and humans: Kimber, 1994; S. Kimber and S. Lindenberg, unpublished), suggesting it could be a widespread component in the implantation process. In this study, we examined whether expression of this epitope in rats showed similar ovarian steroidal control to that demonstrated in mice. Our goal was also to identify other carbohydrate epitopes, expressed by the endometrial epithelium under the control of ovarian steroids, that may be markers of particular (sensitized, receptive, refractory) endometrial epithelial states.

\section{Materials and Methods}

Rats

Sprague-Dawley rats were obtained from either Harlan Industries (Houston, TX) or Harlan Olac (Bicester). Females were housed individually with males of their own strain and mating established by checking for spermatozoa in the vagina (day 1 of pregnancy). On the day required, rats were killed between 14:00 and 15:00 h by i.p. injection of avertin (50 mg kg ${ }^{-1}$ ) or inhalation of chloroform, and the uterine horns dissected and cut into four pieces. They were either immersed in OCT embedding compound (Miles, Elkhart) and snap frozen in liquid nitrogen, or directly snap frozen in liquid nitrogen and stored at $-80^{\circ} \mathrm{C}$ until required for sectioning. Pregnancy was confirmed by flushing embryos from either the oviduct or part of one uterine horn, up to day 5 as appropriate.

\section{Ovariectomy and hormone supplementation}

Female rats were bilaterally ovariectomized and left for 10 days to recover and for endogenous hormone concentrations to subside. The rats were injected (Table 1) with two daily priming s.c. injections of $100 \mathrm{ng}$ oestradiol benzoate, left for 2 days and then injected according to one of the regimens below. In each of groups a-d, rats were killed $18 \mathrm{~h}$ after the final injection. Injections were given daily on days 5, 6 and 7 as follows: (a) controls, three injections of sesame oil only; (b) three injections of $100 \mathrm{ng}$ oestradiol benzoate; (c) three injections of $5 \mathrm{mg}$ progesterone (sensitized); (d) two injections of $5 \mathrm{mg}$ progesterone followed by $5 \mathrm{mg}$ progesterone and $50 \mathrm{ng}$ oestradiol on day 3 (receptive); (e) as in (d) but on days 4 and 5 , two further injections of $5 \mathrm{mg}$ progesterone and $50 \mathrm{ng}$ 
Table 2. Specificity of mouse monoclonal antibodies used in this study

\begin{tabular}{|c|c|c|c|}
\hline $\mathrm{mAb}$ & Isotype & Specificity & Reference \\
\hline 619/1D2 & IgM & LNT & MonoCarb product information \\
\hline P001 & $\operatorname{IgM}$ & $P_{1}$-antigen & Brodin et al. (1988) \\
\hline $\mathrm{P}^{\mathrm{k}} \mathrm{OO2}$ & IgM & $\mathrm{P}^{\mathrm{k}}$-antigen & Brodin et al. (1988) \\
\hline TOO1, BM22 & IgM & $\mathrm{T}$-antigen & Steuden et al. (1985) \\
\hline HoOI & $\operatorname{IgM}$ & $\mathrm{Le}^{\mathrm{b}} / \mathrm{Le}^{\mathrm{y}}$ & Brodin et al. (1987); Enblad et al. (1986) \\
\hline HOO4 & IgM & $\mathrm{Le}^{\mathrm{y} / \mathrm{H} \text {-type-2 }}$ & MonoCarb product information \\
\hline $672 / 7 \mathrm{E} 3$ & $\operatorname{IgM}$ & $\mathrm{Le}^{\mathrm{y}}$ & MonoCarb product information \\
\hline 647/9A2 & $\operatorname{IgM}$ & H-type-2 & MonoCarb product information \\
\hline $667 / 9 \mathrm{E} 9$ & IgM & H-type-I & Kimber et al. (1988); Lindenberg et al. (1990) \\
\hline 630/7H1 & IgM & $\mathrm{Le}^{\mathrm{x}}$ and dimeric $\mathrm{Le}^{\mathrm{x}}$ & Kimber et al. (1988); MonoCarb information \\
\hline $\mathrm{A} 003 / 5$ & $\operatorname{IgM}$ & Blood group A & Chen and Kabat (1985); Bouhours et al. (1987) \\
\hline B005/6 & $\operatorname{IgM}$ & Blood group B & MonoCarb product information \\
\hline
\end{tabular}

Table 3. Carbohydrate structures investigated

\begin{tabular}{|c|c|}
\hline LNT & Gal $\beta 1-3 G l c N A c \beta 1-3$ Gal $\beta 1-4 \mathrm{Glc}$ \\
\hline$P_{1}$-antigen & Gal $\alpha 1-4 \mathrm{Gal} \beta 1-4 \mathrm{Glc} N A \mathrm{c} \beta 1-3 \mathrm{Gal} \beta 1-4 \mathrm{Glc}$ \\
\hline $\mathrm{P}^{\mathrm{k}}$ antigen & Gal $\alpha 1-4 \mathrm{Gal} \beta 1-4 \mathrm{Glc}$ \\
\hline T-antigen & Gal $\beta 1-3 \mathrm{Gal} N A c \alpha 1-$ \\
\hline $\mathrm{Le}^{\mathrm{b}}$ & Fuc $\alpha 1-2 \mathrm{Gal} \beta 1-3[$ Fuc $\alpha 1-4] \mathrm{GlcNAc} \beta 1-$ \\
\hline$L e^{y}$ & Fuc 1 1-2Gal $\beta 1-4[$ Fuc $\alpha 1-3]$ GlcNAc $\beta 1-$ \\
\hline H-type-1 & Fuc $\alpha 1-2 \mathrm{Gal} \beta 1-3 \mathrm{Glc} N A \mathrm{c} \beta 1-$ \\
\hline H-type-2 & Fuc $\alpha 1-2 \mathrm{Gal} \beta 1-4 \mathrm{GlcN} A c \beta 1$. \\
\hline $\mathrm{Le}^{\mathrm{x}}$ & Gal $\beta 1-4[$ Fuc $\alpha 1-3]$ GlcNAc $\beta 1-$ \\
\hline Blood group A & Gal $\alpha 1-3[$ Fuc $\alpha 1-2] \mathrm{Gal} \beta 1-3 / 4 \mathrm{GlcNAc}$ \\
\hline Blood group B & GalNAc $\alpha 1-3[$ Fuca 1-2] Gal $\beta 1-3 / 4 \mathrm{GlcNAC}$ \\
\hline
\end{tabular}

oestradiol were given and the rats killed $48 \mathrm{~h}$ later (refractory). All hormone injections were given at $16: 00 \mathrm{~h}$ in a $0.1 \mathrm{ml}$ volume of sesame oil.

\section{Immunocytochemistry}

A double-layer immunofluorescence technique was used as reported previously (Kimber et al., 1988; White and Kimber, 1994). A minimum of three rats was used for staining for each steroid treatment, or two from each stage of pregnancy. When staining varied between days of pregnancy, a minimum of three rats was used for each day. Primary antibodies were mouse monoclonals (mAbs) from MonoCarb AB (formerly BioCarb $A B$ ), Lund, recognizing a number of type 1 and type 2 carbohydrate antigens as shown in Tables 2 and 3. Transverse sections, $7 \mu \mathrm{m}$ thick, of uterus from a minimum of two different areas at least $20 \mu \mathrm{m} \times 7 \mu \mathrm{m}$ apart were stained with each antibody. On days 7 and 8 of pregnancy, areas adjacent to the embryo within the decidualized swelling and between implantation sites were examined. No variation between these regions was detected except for the $\mathrm{T}$ and $\mathrm{A}$ antigens (see Results). A fluorescein isothiocyanate (FITC) goat anti-mouse antibody (Sigma, Poole) specific for the isotype of the primary antibody was used for the second layer. Antibody binding was observed in a Leitz Dialux epifluorescence microscope and photographed.

\section{Results}

\section{Pregnancy}

The staining patterns detected with different $m A$ Abs during pregnancy are summarized in Table 4 . The $\mathrm{P}^{l}$ and $\mathrm{P}_{\mathrm{k}}$ antigens were not detected on the epithelium or in stromal cells on any day of pregnancy. Similarly, no staining was observed in the uterus with a mAb to the unfucosylated backbone structure Gal $\beta 1-3$ GlcNAc $\beta 1-3 \mathrm{Gal} \beta 1-4 \mathrm{Glc}$ (LNT) used routinely as a negative control (Table 3 ).

$T$ antigen. The $T$ antigen was not detected on the endometrial epithelium between days 2 and 6 of pregnancy, but on days 7 and 8 moderate apical staining was observed on approximately $75 \%$ of luminal cells (Fig. Ia, b) adjacent to the decidualized stroma. The epithelium in the interimplantation site was negative as were most glands, although a few showed apical staining similar to that found in the lumen. Individual scattered cells in the stroma were stained at all stages but were particularly marked on day 2 , and many were found immediately basal to the epithelium (Fig. 1a).

$L e^{y}$ and $L e^{b}$. Antibodies to the difucosylated antigens $\mathrm{Le}^{\mathrm{b}}$ and $\mathrm{Le}^{\mathrm{y}}$ (H0O1, H004, 672/7E3) stained the endometrial epithelium throughout pregnancy (Fig. Ic-h), although the appearance of staining on day 7 was different from that observed earlier (Fig. Ih). While up to day 6 the epithelial cells reacted uniformly with the three mAbs, on day 7 the staining pattern was heterogeneous, with some cells heavily stained but others only dimly fluorescent or unstained. This appearance was marked with $\mathrm{H} 001$ and least noticeable with $672 / 7 \mathrm{E} 3$. The antibodies stained both the cytoplasm and the cell surface but the resolution was insufficient to ascertain whether the membrane itself was being stained. Faint filamentous fluorescence in the lumina of glands and the cavity of the lumen, not seen in the controls, indicated reaction with secreted material. Stromal cells were unstained at all stages.

H-type-2. Staining was negative on glands and lumen on day 2 of pregnancy (Fig. 1i). It was first observed on the 
Table 4. Summary of expression of carbohydrate antigens in the rat endometrial epithelium during pregnancy

\begin{tabular}{|c|c|c|c|c|c|c|c|c|}
\hline \multirow[b]{2}{*}{ Antigen } & \multirow[b]{2}{*}{$\mathrm{E} / \mathrm{S}$} & \multicolumn{7}{|c|}{ Day of pregnancy } \\
\hline & & 2 & 3 & 4 & 5 & 6 & 7 & 8 \\
\hline LNT & $\mathrm{E} / \mathrm{S}$ & - & - & - & - & - & - & - \\
\hline$P_{1}$ & $\mathrm{E} / \mathrm{S}$ & - & - & - & - & - & - & - \\
\hline $\mathrm{P}^{\mathrm{I}}$ & $\mathrm{E} / \mathrm{S}$ & - & - & - & - & - & - & - \\
\hline \multirow[t]{2}{*}{$\mathrm{T}$} & $\mathrm{E}$ & - & - & - & - & - & $+^{\mathrm{ab}}$ & $+{ }^{a b}$ \\
\hline & $\mathrm{S}$ & ++ & + & + & + & + & + & + \\
\hline \multirow[t]{2}{*}{$\mathrm{Le}^{\mathrm{y}} / \mathrm{Le}^{\mathrm{b}}$} & $\mathrm{E}$ & ++ & ++ & ++ & ++ & ++ & ++ or - & + \\
\hline & S & - & - & - & - & - & - & - \\
\hline \multirow[t]{2}{*}{ H-type-2 } & $\mathrm{E}$ & - & $+{ }^{a}$ or - & $+{ }^{a}$ & $+{ }^{a}$ & - & - & - \\
\hline & $\mathrm{S}$ & - & - & - & - & - & - & - \\
\hline \multirow[t]{2}{*}{ H-type-1 } & $\mathrm{E}$ & + & + & ++ & ++ & + or - & ++ & ++ \\
\hline & $\mathrm{S}$ & - & - & - & - & - & - & - \\
\hline \multirow[t]{3}{*}{$\mathrm{Le}^{\mathrm{x}}$} & $\mathrm{El}$ & + & + or - & + or - & + or - & ++ & ++ & ++ \\
\hline & $\mathrm{Eg}$ & - & - & - & - & - & - & - \\
\hline & $\mathrm{S}$ & - & - & - & - & - & - & - \\
\hline \multirow[t]{3}{*}{ A } & $\mathrm{El}$ & - & - & - & - & ++ or - & ++ or - & $+1-$ or $-b$ \\
\hline & Eg & - & + or - & ++ & ++ & ++ & ++ & ++ \\
\hline & $S$ & - & - & - & - & - & - & - \\
\hline \multirow[t]{2}{*}{ B } & $E$ & ++ & ++ & ++ & ++ & ++ & ++ & ++ \\
\hline & $\mathrm{S}$ & + or - & ++ or - & ++ or - & + or - & + or - & + or - & + or - \\
\hline
\end{tabular}

E/S: Epithelium or stroma; Eg: glands; El: luminal epithelium; ${ }^{a}$ predominently apical; 'badjacent to decidua.

luminal and glandular epithelium on the morning of day 3 of pregnancy (Fig. 1j). From late day 3 to day 5 of pregnancy, the apical surface of the luminal epithelium stained strongly (Fig. 1j, k). The fluorescence was localized in the apical cytoplasm, with weaker lateral staining. Staining in the glands was very weak but reactivity was detected on apical surfaces. The pattern of luminal fluorescence was patchy; some cells were unstained, particularly late on day 3 of pregnancy. On days 6-8 of pregnancy, the antigen was absent (Fig. 11). Staining of secretions within the lumen could not be detected and no antibody binding to cells of the stroma was observed.

H-type-1. The mAb 667/9E9 stained the luminal epithelium throughout pregnancy. On day 2 of pregnancy, fluorescent staining was predominantly apical in both glands and lumen (Fig. 2a). By day 3 all surfaces and the cytoplasm were stained (Fig. 2b) and there was a marked increase in staining intensity on days 4 and 5 . The fluorescence was slightly reduced and variable by day 6 and became patchy on the glands. However, on day 7 of pregnancy, staining was stronger and more uniform on all aspects of the cell surface and cytoplasm (Fig. 2c), although unreactive areas remained in both glands and lumen. Filamentous material within the cavity of the lumen reacted with the mAb (Fig. 2b) except on days 5 and 6 . The stroma did not react at any stage.

$L e^{x}$. Expression of the $\mathrm{Le}^{\mathrm{x}}$ antigen on the luminal epithelium depended on the day of pregnancy. On day 2 , the cytoplasm and all cell surfaces except basal were stained (Fig. 2d). Most luminal epithelial cells were still strongly stained apically on days 3-5 (Fig. 2e), although there were now patches of unstained cells. Basal staining was low or absent and cytoplasmic staining was weaker than on day 2 . The intensity of staining was high on all surfaces and cytoplasm on days 6-8 (Fig. 2f). Staining of glands was negligible on all days of pregnancy. $m A b$-reactive material within the lumen could sometimes be detected but the stroma was always negative.

$A$ antigen. Staining with the antibodies to the $\mathrm{A}$ antigen showed a stage-specific pattern. The luminal epithelium was negative on all surfaces (Fig. $2 g, i, j$ ) until day 6 , when fluorescence became strong on the apical surface and cytoplasm (Fig. 2k). The lumen had a striped appearance, with strongly stained cells interspersed with unstained cells. This appearance was retained on day 7 while on day 8 , staining was weaker and practically negative adjacent to the decidua (Fig. 2l). In some cases, faintly fluorescent material in the lumen was detectable on days 6 and 7 . On day 2 of pregnancy, the glands were negative and some remained negative on day 3 . In contrast to the lumen, most glands on day 3 and all glands from day 4 onwards were strongly stained on all surfaces (Fig. $2 \mathrm{~h}$, i). No staining was detected in the stroma.

$B$ antigen. The $B$ histo-blood group antigen was present throughout pregnancy on the luminal and glandular epithelium. The fluorescence intensity was high at all stages with little variation (Fig. 3a, b). Scattered stromal cells, particularly those adjacent to the lumen on days 3 and 4 of pregnancy, also stained for the $B$ antigen. No preference for a particular (for example, mesometrial or antimesometrial) region of the stroma could be detected. 

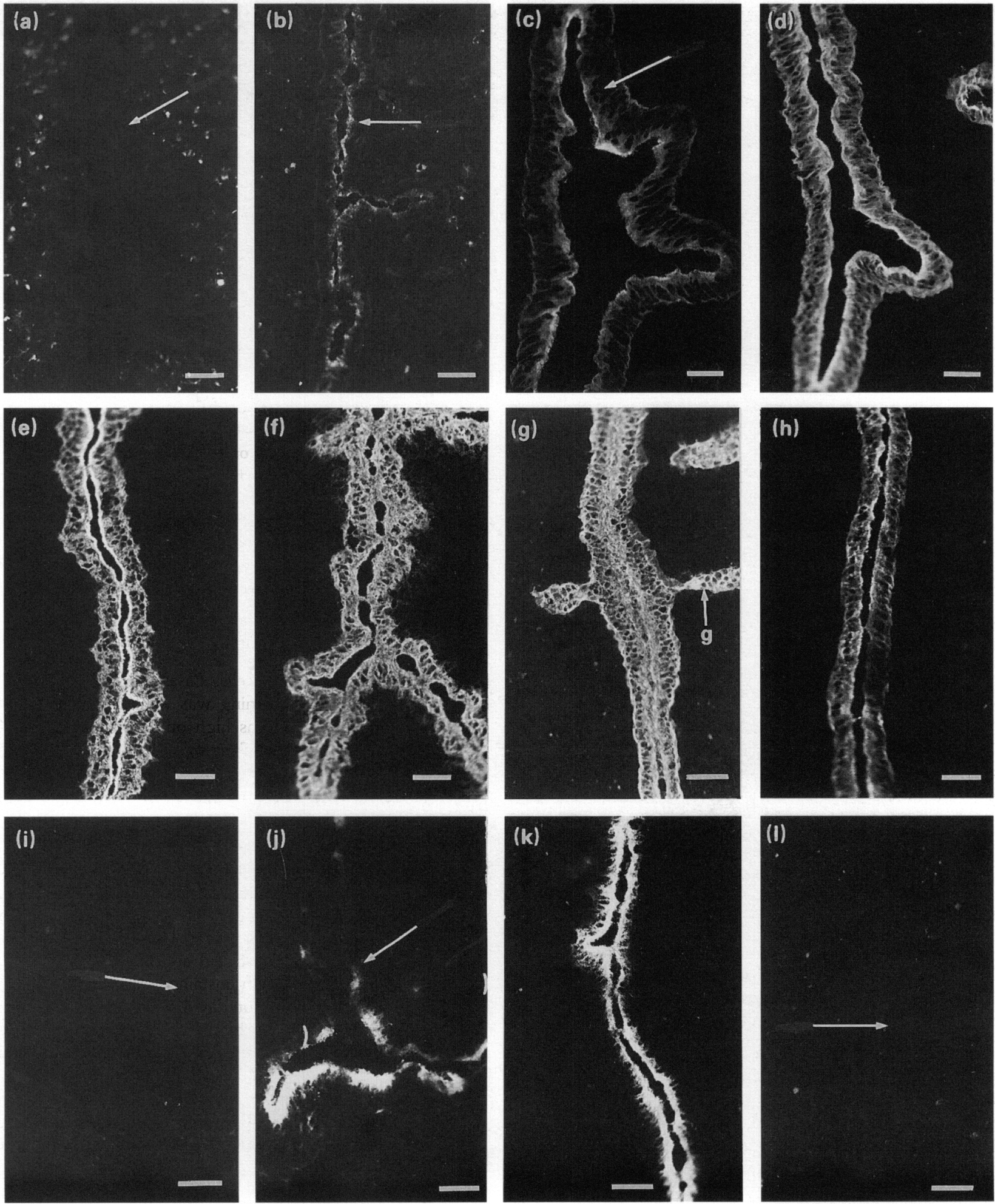

Fig. 1. Staining of the rat endometrium during early pregnancy with mAbs recognizing carbohydrate antigens (Tables 2 and 3 ). (a) Staining with mAb TOOI on day 2 of pregnancy (T antigen); (b) mAb TOOI on day 7 of pregnancy, note staining of luminal epithelium: (c) day 2 of pregnancy stained with mAb $100 \mathrm{I}$ (l." l. $e^{\prime \prime}$ ): (d) staining on day 3 of pregnancy with mAb HoO4 (Le", H-type-2): (e) staining

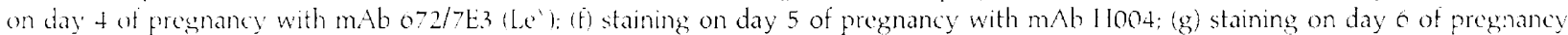

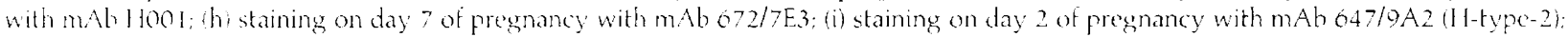
(j) staining on day 3 of pregnancy with mAb o $77 / 9 \mathrm{~A} 2$; ( $\mathrm{k}$ ) staining on day 4 of pregnancy with mAb 647/9A2; (1) staining on day of presnancy with mAb ot 70 A2. Arrows indicate luminal epithelium: $g$ indicates gland. Scale bars represent $40 \mu \mathrm{m}$. 

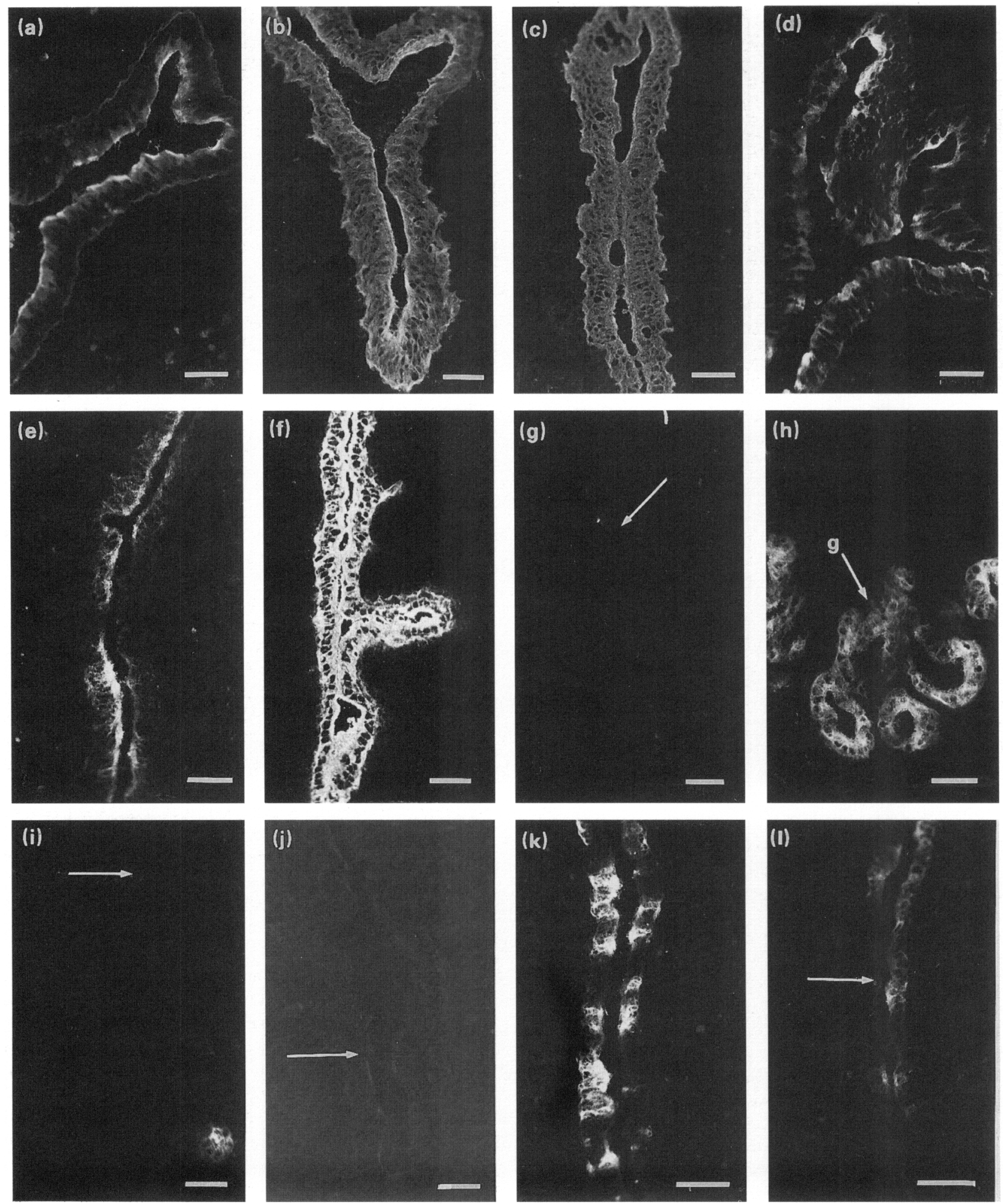

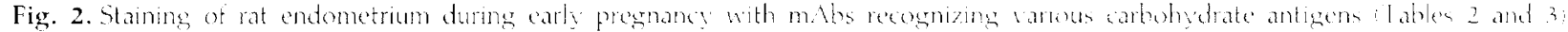

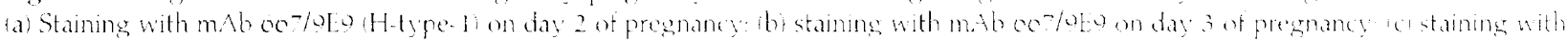

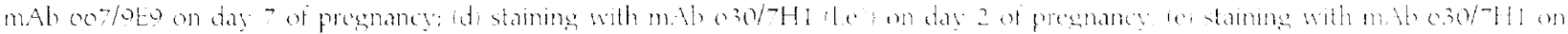

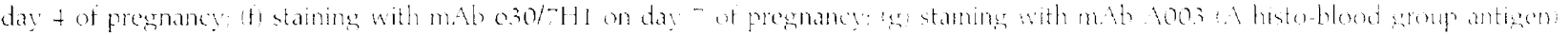

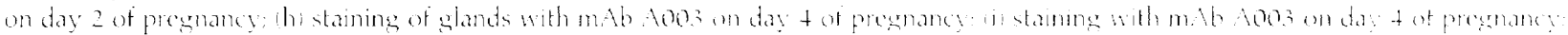

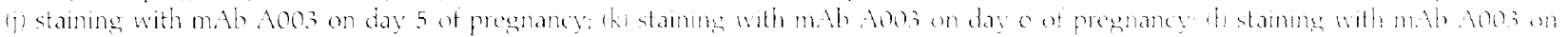

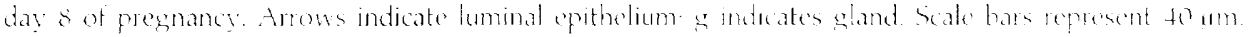



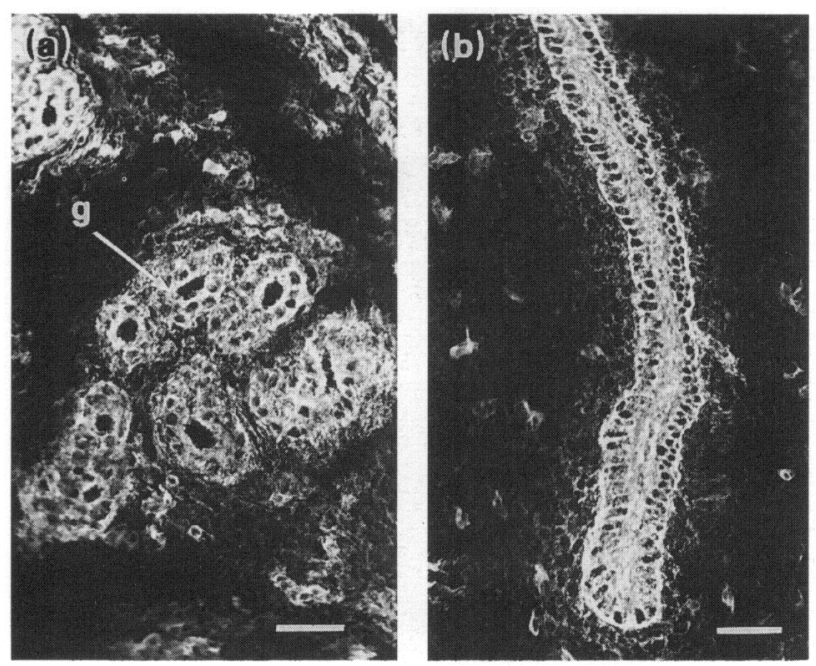

Fig. 3. Staining of rat endometrium during early pregnancy with $m A b$ B006 to the histo-blood group B antigen (Tables 2 and 3). (a) Staining on day 4 of pregnancy; (b) staining on day 6 of pregnancy. Arrows indicate luminal epithelium; $g$ indicates gland. Scale bars represent $40 \mu \mathrm{m}$.

\section{Ovariectomized rats}

The staining patterns detected with different mAbs after ovariectomy are summarized in Table 5. No staining was observed with antibodies to the $T, \mathrm{P}^{\mathrm{k}}, \mathrm{P}_{1}$ or LNT antigens on the endometrial epithelium in ovariectomized rats after any treatment. Unlike the situation in pregnant animals, scattered cells that reacted with antibody to the $\mathrm{T}$ antigen were never detected in the stroma (Fig. 4a), independent of the type of treatment (Table 1).

$L e^{y}$ and $L e^{b}$. The antibodies to $\mathrm{Le}^{\mathrm{y}}$ and $\mathrm{Le}^{\mathrm{b}}$ (Table 2) stained the luminal and glandular epithelia after all treatments (Fig. $4 \mathrm{~b}-\mathrm{f}$ ). Staining of the luminal epithelium appeared not to be altered by any of the hormonal regimens (Table 1). Antigen was detected in the cytoplasm, particularly apically, and at all cell surfaces. Stained material within the lumen was also detected (Fig. 4c). Staining was reproducibly high and showed little intracellular variation.

These antibodies also stained the glands, but in rats treated with progesterone (sensitized) or progesterone followed by a single injection of progesterone and oestrogen (receptive), staining was greatly reduced or absent in the apical region of the glandular epithelium (Fig. 4e). Progesterone followed by three daily injections of progesterone plus oestrogen (refractory) gave more variable glandular staining with strong apical fluorescence for all three mAbs in only one rat (Fig. 4f). Deep in the endometrium (but not adjacent to the lumen), lateral glandular cell surfaces and cytoplasm were unstained and basal surfaces faintly stained in all animals. Although mAbs to these difucosylated structures did not stain most of the stroma, the fluorescence sometimes appeared to have bled from the basal surface of luminal or glandular epithelium into the adjacent stroma, suggesting either basal secretion or diffusion.
H-type-2. In animals treated with sesame oil or oestrogen alone there was generally no staining (Fig. 4g). However, after treatment with progesterone alone, patches of apical cytoplasmic fluorescence were present (Fig. 4h), varying in extent and intensity between animals. Intervening stretches of epithelium were negative. After progesterone treatment followed by one or three injections of progesterone plus oestrogen, areas of lumen were again found in which apical surfaces and cytoplasm were brightly stained (Fig. 4i, j). These stretches were often more extensive than after progesterone alone. The glands were unstained or occasionally reacted weakly on the apical aspect.

H-type-1. In vehicle or oestrogen treated rats, weak punctate, patchy staining was detectable on apical, but not lateral or basal surfaces of the luminal and glandular epithelium (Fig. $4 k, 1)$. However, in rats given progesterone alone, the cells stained on all surfaces (Fig. $5 \mathrm{a}$ ), the intensity being greatest at apical surfaces and in the cytoplasm. This pattern was little changed in rats given progesterone followed by a single injection of progesterone plus oestrogen (Fig. 5b), but the fluorescence was more uniform and all surfaces and cytoplasm were brightly stained. Staining of glandular, but not luminal, epithelium was diminished after three injections of progesterone plus oestrogen (refractory, Fig. 5c).

$L e^{x}$ antigen. The luminal epithelium stained for Le ${ }^{x}$ after all hormone treatments or injection of the vehicle (Fig. $5 \mathrm{~d}-\mathrm{g}$ ). The apical region of the luminal epithelium always stained most strongly. Fluorescence was consistently brightest in rats treated with progesterone followed by three injections of oestrogen and progesterone (Fig. $5 \mathrm{~g}$ ). However, the difference between this and other treatments was only noticeable at the lateral and basal surfaces and in the cytoplasm. The glands stained little after any treatment, although occasional fluorescence was detected at the apices of individual cells, suggesting secretory material. This was most marked after progesterone followed by a single, or more often three, injections of progesterone plus oestrogen. Little mAb-reactive secreted material was detected, except after the latter treatment, and no reactivity was detected in the stroma.

A antigen. Both luminal and glandular epithelia were negative in rats treated with vehicle or oestrogen (Fig. $5 \mathrm{~h}$, i). In rats treated with progesterone alone, the luminal epithelium was also almost always negative (Fig. 5j) but the glands were strongly stained on all surfaces and in the cytoplasm. After progesterone followed by a single dose of progesterone plus oestrogen, the luminal epithelium was again negative (Fig. 5k). In contrast, in rats given progesterone followed by three injections of progesterone plus oestrogen, the luminal epithelial staining had a striking, reproducible, banded appearance (Fitg. 5l). This suggested apical cytoplasmic reactivity, possibly of mucous material, which was not present in every epithelial cell. In contrast, the glands were uniformly brightly stained, while the stroma was negative.

$B$ antigen. As for pregnant animals, the $B$ antigen was expressed uniformly on the endometrial epithelium in all animals (Fig. 6a, b). There was a slight reduction on the 
Table 5. Summary of expression of carbohydrate antigens in the rat endometrial epithelium after ovariectomy and hormone replacement

\begin{tabular}{|c|c|c|c|c|c|c|}
\hline Antigen & $\mathrm{E} / \mathrm{S}$ & Oil & $\mathrm{O}$ & $\begin{array}{l}\text { Treatment } \\
\text { P }\end{array}$ & $\mathrm{P}+\mathrm{O}$ & $\mathrm{R}$ \\
\hline LNT & $\mathrm{E} / \mathrm{S}$ & - & - & - & - & - \\
\hline $\mathrm{P}^{1}$ & $\mathrm{E} / \mathrm{S}$ & - & - & - & - & - \\
\hline$P_{k}$ & $\mathrm{E} / \mathrm{S}$ & - & - & - & - & - \\
\hline $\mathrm{T}^{\mathrm{k}}$ & $\mathrm{E} / \mathrm{S}$ & - & - & - & - & - \\
\hline \multirow[t]{3}{*}{$\mathrm{Le}^{\mathrm{y}} / \mathrm{Le}^{\mathrm{b}}$} & $\mathrm{El}$ & ++ & ++ & ++ & ++ & ++ \\
\hline & $\mathrm{Eg}$ & ++ & ++ & + or $-{ }^{c}$ & + or $-{ }^{c}$ & + or $-{ }^{c}$ \\
\hline & $S^{d}$ & - & - & - & - & - \\
\hline \multirow[t]{3}{*}{ H-type-2 } & El & - & - & $+{ }^{a}$ or - & $+{ }^{a}$ or - & $+{ }^{a}$ or - \\
\hline & $\mathrm{Eg}$ & - & - & - & - & - \\
\hline & $\mathrm{S}$ & - & - & - & - & - \\
\hline \multirow[t]{3}{*}{ H-type- 1} & $\mathrm{El}$ & $+{ }^{a}$ & $+{ }^{a}$ & + & ++ & ++ \\
\hline & $\mathrm{Eg}$ & $+{ }^{a}$ & $+{ }^{a}$ & + & ++ & + \\
\hline & $S$ & - & - & - & - & - \\
\hline \multirow[t]{3}{*}{$\mathrm{Le}^{\mathrm{x}}$} & El & + & + & + & + & $++b$ \\
\hline & $\mathrm{Eg}$ & - & - & - & - or $+{ }^{a}$ & - or $t^{a}$ \\
\hline & $S$ & - & - & - & - & - \\
\hline \multirow[t]{3}{*}{ A } & El & - & - & - & - & ++ or - \\
\hline & $\mathrm{Eg}$ & - & - & + & + & ++ \\
\hline & $S$ & - & - & - & - & - \\
\hline \multirow[t]{2}{*}{ B } & $\mathrm{E}$ & ++ & ++ & ++ & ++ & ++ \\
\hline & $S$ & + or - & + or - & + or - & + or - & + or - \\
\hline
\end{tabular}

Oil: vehicle control (treatment a in Table 1); $\mathrm{O}$ : oestrogen (treatment $\mathrm{b}$ in Table 1); $\mathrm{P}$ : progesterone (treatment $\mathrm{c}$ in Table 1); $\mathrm{P}+\mathrm{O}$ : progesterone followed by a single injection of progesterone + oestrogen (receptive, treatment $d$ in Table 1); $R$ : progesterone followed by three injections of oestrogen + progesterone (refractory: treatment e in Table 1).

E/S: Epithelium or stroma; Eg: glands; El: luminal epithelium; ${ }^{a}$ predominently apical; ${ }^{b}$ glands less intense; 'deep glands unstained except basally; ${ }^{d}$ some staining of stroma adjacent to epithelium.

basal-lateral surface and in general cytoplasmic staining after the vehicle or oestrogen. Cells in the stroma with various morphologies also stained (Fig. 6a).

\section{Discussion}

Several carbohydrate epitopes based on Gal $\beta 1-G l c N a c$ chains were previously demonstrated as markers of endometrial epithelium in mice (Kimber et al., 1988, 1994). Similar antigens have now been examined on rat endometrium and those specific to different stages of pre- and peri-implantation pregnancy have been identified. These will help define changes in the endometrium in response to hormones and other regulatory agents and expand our understanding of ovoreceptivity.

Two types of sequence may be formed from repeat Gal $\beta 1-$ GlcNAc units: lacto (type 1) sequences based on Gal $\beta 1-$ $3 \mathrm{GlcNAc} \beta 1-3 \mathrm{Gal} \beta 1-3$, and neolacto (type 2 ) sequences based on Gal $\beta 1-4 \mathrm{Glc} N A c \beta 1-3 \mathrm{Gal} \beta 1-3$ chains. These structures form linear or branched chains attached to lipids or proteins and, together with globo-series carbohydrates, constitute backbone chains for the attachment of terminal histo-blood group antigens (Hakomori, 1989; Holgersson et al., 1992). In humans these are both tissue and blood group antigens, but in rodents they exist as tissue antigens (Oriol et al., 1992). The staining pattern generated by a mAb recognizing a carbohydrate antigen may result from the summed distribution of the same structure on several different molecules. In addition, changes in the detection of an antigen may reflect its availability to antibody binding as a result of masking or unmasking.

In rat endometrium, expression of histo-blood group antigens was generally detected exclusively on epithelial cells, as in mice (Kimber et al., 1988; Babiarz and Hathaway, 1988). However, the $\mathrm{T}$ and $\mathrm{B}$ antigens were expressed on both epithelial and stromal cells in rats. The $\mathrm{T}$ antigen was detected on luminal epithelium only between days 7 and 8 of pregnancy adjacent to decidualized stroma, 1.5-2.5 days after implantation. No staining was detected in ovariectomized rats treated to give a uterus refractory to embryo implantation (Psychoyos, 1973). Thus, expression may occur only after implantation, possibly triggered by an embryonic factor, or transiently as the epithelium passes from the receptive to refractory state. By examining ovariectomized rats relatively late in the refractory period (approximately $64 \mathrm{~h}$ after the end of receptivity), we may have missed the transient period of $\mathrm{T}$ antigen expression. The $P_{I}$ and $P^{k}$ antigens and unsubstituted terminal Gal $\beta 1-$ 3 GlcNAc were detectable on endometrial epithelia, as in the mouse (Kimber et al., 1988 and unpublished data). These antigens are probably substituted with fucose or sialic acid, which mask mAb binding.

Antigens expressed throughout pregnancy and irrespective of hormone regimen after ovariectomy include those recognized by H001, H0O4 and 672/7E3, which stained with a 

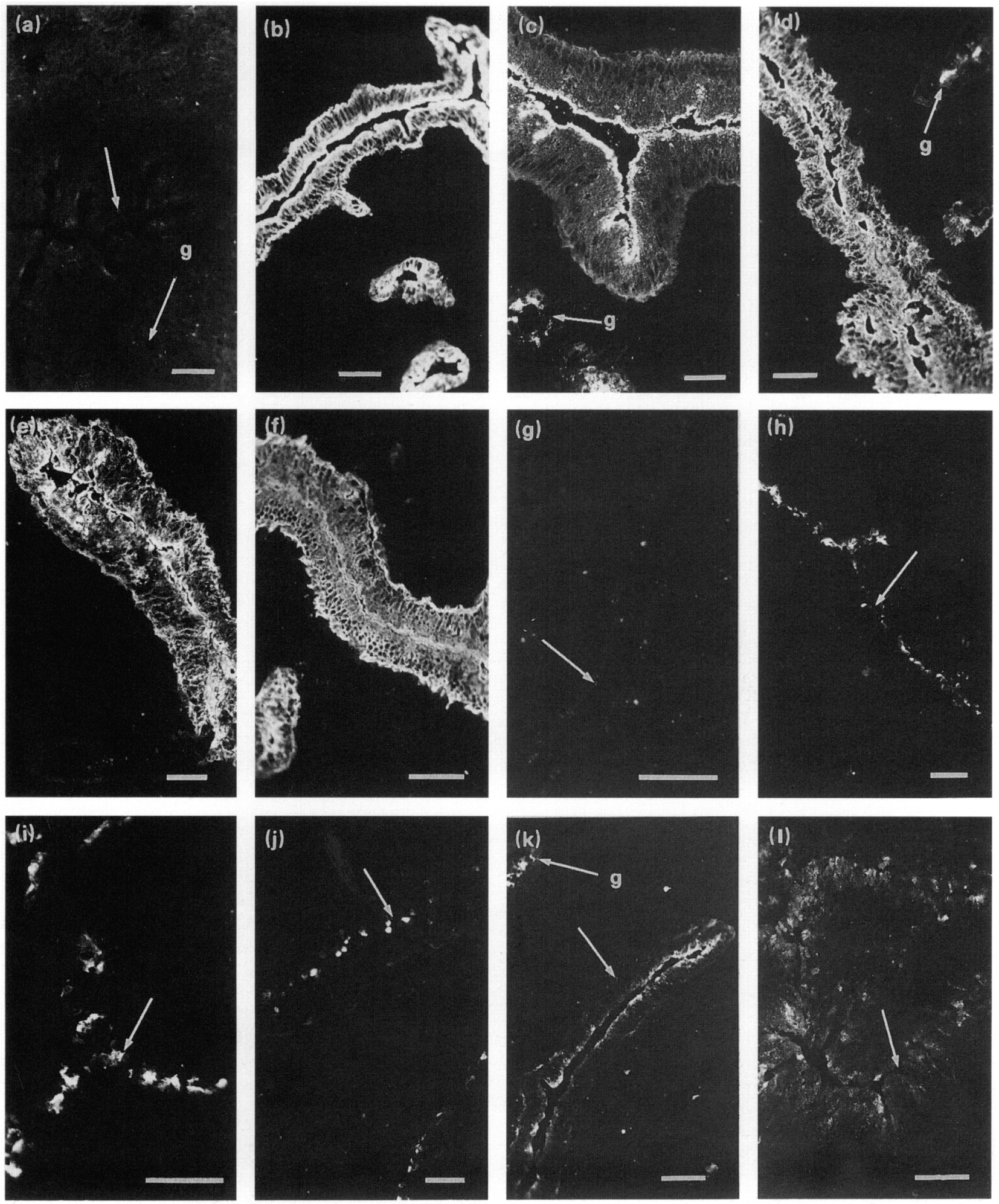

Fig. 4. Staining of rat endometrium after ovariectomy and homone supplementation with mAbs recognizing various carbohydrate

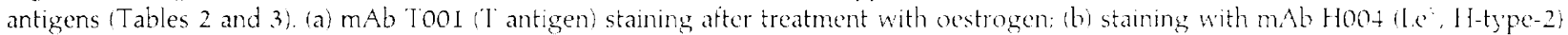
atter treatment with the vehicle only: (c) staining with $\mathrm{mAb}$ (072/7E3 (1.e) after treatment with oestrogen: (d) staining with mAb HoO (Le, Le $)$ after progesterone treatment; (e) staining with 672/7E.3 after progesterone and a singite injection of progesterone + oestrogen (receptive); (f) staining with $\mathrm{HOO} 4$ after treatment with progesterone followed by three daily injections of oestrogen + progesterone (refractory): (g) staining with $\mathrm{mAb} 647 / 9 \mathrm{~A} 2(\mathrm{H}$-type-2) after treatment with the wehicle only: (h) staining with $\mathrm{mAb} 647 / 9 \mathrm{~A} 2$ after treatment with progesterone: (i) staining with $\mathrm{mAb} 047 / 9 \mathrm{~A} 2$ after progesterone and a single injection of progesterone +oestrogen (receptive): (j) staining with $\mathrm{mAb} 0.7 / 9 \mathrm{~A} 2$ after treatment with progresterone tollowed by three daily injections of oestrogen + progesterone (refractory): (k) staining with $\mathrm{mAb}$ ocologe (1)-type-1) after treatment with vehicle alone; (b) staining with $667 / 9 \mathrm{E} 9$ after treatment with oestrogen. Arrows indicate luminal epithelium; g indicates gland. Scale bars represent 40 , $4 m$. 

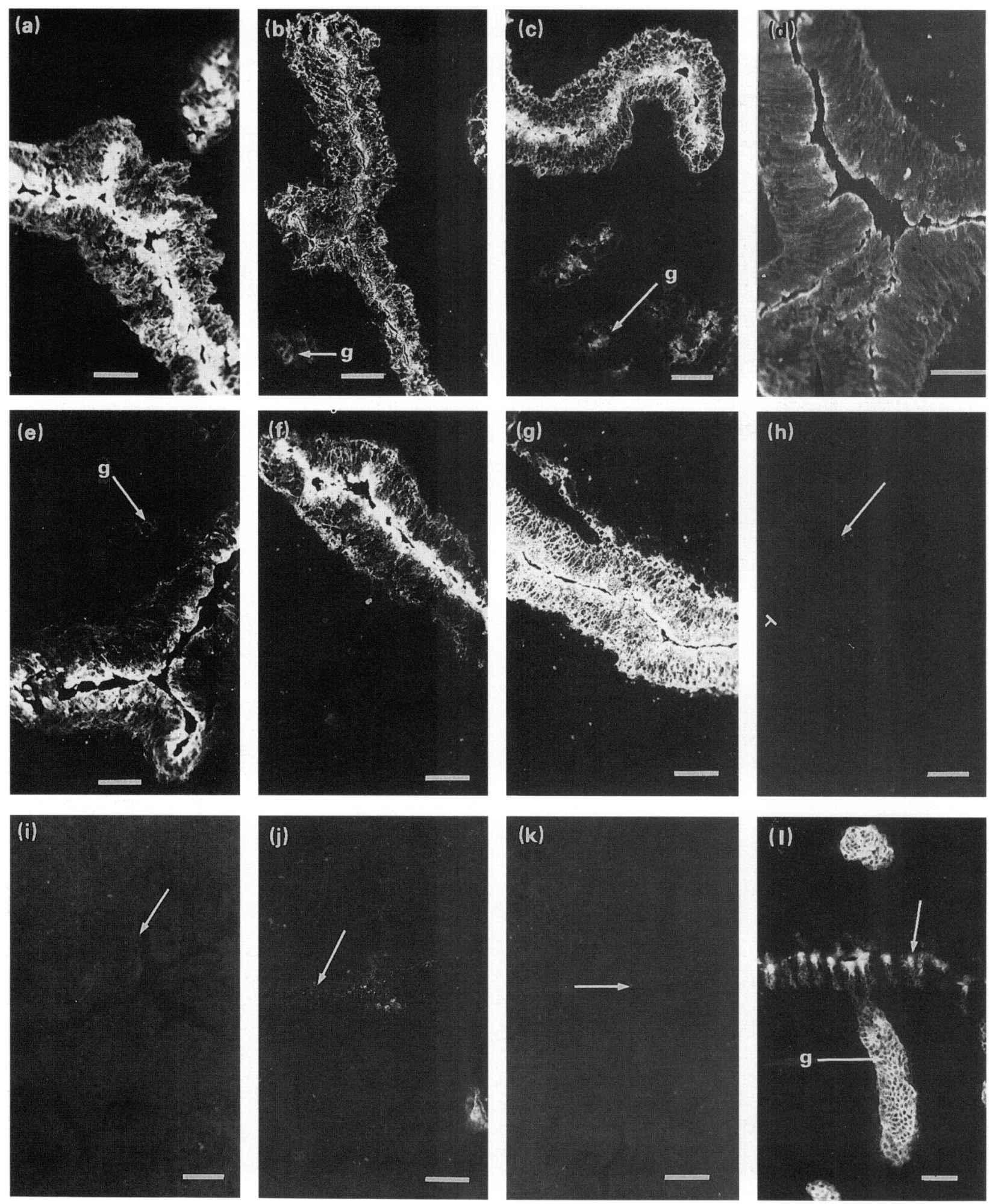

Fig. 5. Staining of rat endometrium after ovariectomy and homone supplementation with mAbs recognizing various carbohydrate antigens (Tables 2 and 3). (a) Staining with $\mathrm{mAb} 607 / 9 \mathrm{Eg}$ (1)-type-1) after treatment with progresterone: (b) staining with mAb oc $7 / 9 E^{2}$ )

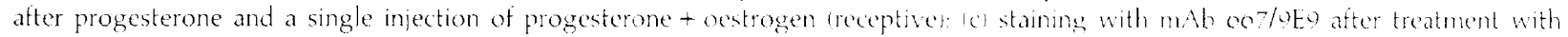

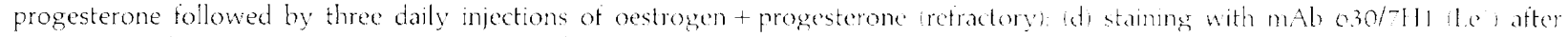
treatment with oestrogen: (e) staining with $630 / 711$ after treatment with progesterone: (f) staining with o.30/7l!l after tratment with progesterone followed by an injection of progesterone +oestrogen: (g) staining with $0.30 / 7 \mathrm{H}$ : after treatment with progesterone followed by three daily injections of oestrogen + progesterone tretractoryt the staining with mAb. A003 A histo-blond group antigen after treatment with the vehicle alone: (i) staining with mAb A003 after treatment wilh oestrogen: (i) staining with m.Ab AOO3 atter treatment with progesterone; $(k)$ staining with $m$ Ab A003 after progesteront and a single injection of progesterone + ocstrogen (receptive): (1) staining with $\mathrm{mAb}$ A003 atter treatment with progesterone followed by thees daily injections of oestrogen + progesterone (refractory). Arrows indicate luminal epithelium; gr indicates gland. Scale bars represent to $u$ m. 

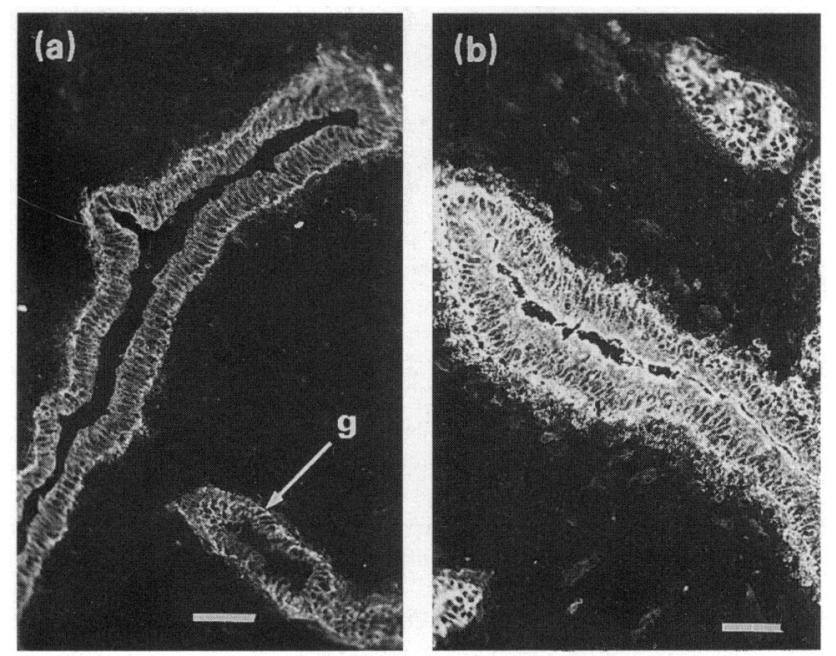

Fig. 6. Staining of rat endometrium after ovariectomy and hormone supplementation, with $\mathrm{mAbs}$ recognizing various carbohydrate antigens (Tables 2 and 3). (a) Staining with mAb Boo6 (B histo-blood group antigen) after treatment with progesterone; (b) staining with $\mathrm{mAb}$ B006 after treatment with progesterone followed by three daily injections of oestrogen + progesterone (refractory). Arrows indicate luminal epithelium; $g$ indicates gland. Scale bars represent $40 \mu \mathrm{m}$.

similar pattern. These mAbs have overlapping specificity for $\mathrm{Le}^{y}$ (Table 2), making it probable that they all recognize $\mathrm{Le}^{y}$ in rat endometrial epithelium. On the luminal epithelium of mice, staining with $\mathrm{HOO1}$ and $\mathrm{HOO} 4$ varied little during the preimplantation period, or after ovariectomy and different steroid treatments (Kimber et al., 1988; Kimber and Lindenberg, 1990). However, some progesterone-mediated downregulation occurred in the glands of ovariectomized rats. The B histoblood group antigen was also expressed uniformly in endometrial epithelium irrespective of stage. Stromal reactivity was marked in rats, in contrast to mice, where this antigen is not expressed in endometrium but is a marker of trophoblast and visceral endoderm (Brown et al., 1993).

Similarly the A histo-blood group antigen is absent from the endometrial epithelium of mice (Kimber et al., 1988) but present on that of the rat. Progesterone stimulated expression in the glands of pregnant and ovariectomized rats. Luminal epithelial reactivity correlated with the refractory period, being strong in rats given progesterone followed by three injections of progesterone plus oestrogen. It was undetectable on day 5 of pregnancy, strong on days 6 and 7 and negligible on day 8 . Thus, this antigen seems to be a useful marker for initiation of the refractory period in rats, although it is absent after implantation in pregnant animals.

The H-type- $\mathrm{I}$ antigen appeared to be stimulated by progesterone on the ovariectomized rat endometrial epithelium, rather than oestrogen as in mice (Kimber and Lindenberg, 1990; Kimber et al., 1994; White and Kimber, 1994). Nevertheless, the expression patterns in pregnant rats and mice are not dissimilar. Maximum staining in rats occurred between days 3 and 5 of pregnancy, before implantation on day 5.5, while in the mouse it occurred between days 2 and 4 with implantation on day 4.5-5. However, the less patchy, non-punctate staining pattern in rats around the time of implantation suggests the epitope may be carried on different types of molecules. Furthermore, in rats, the antigen could still be demonstrated up to day 8 , or in refractory ovariectomized animals, while in mice, staining was weak or negligible by day 6 of pregnancy (Kimber et al., 1988). Thus, there are clear differences in control of H-type- 1 expression between these two rodents. Whether this antigen functions in the attachment of the embryo at implantation in rats, as appears to be the case in mice (Lindenberg et al., 1988; Kimber et al., 1993, 1994), remains unresolved.

Expression of the H-type- 2 antigen was stimulated by progesterone in ovariectomized rats and correlated with progesterone sensitization in pregnancy. Retention of detectable antigen in the refractory luminal endometrial epithelium suggests it is not a reliable marker of progression from a receptive to refractory epithelium. Rather, its absence on day 6 of pregnancy may indicate that implantation has been successfully initiated. Addition of terminal GalNAc to an $\mathrm{H}$ precursor produces the A histo-blood group antigen (Table 3 ) that appears on the luminal epithelium between days 5 and 6 of pregnancy, when the H-type- 2 antigen is absent. Thus, disappearance of $\mathrm{H}$-type- 2 may result from masking by terminal GalNAc.

Strong Le $e^{x}$ staining on the luminal epithelium on day 2 of pregnancy and in oestrogen-treated ovariectomized rats suggests oestrogen stimulation. Only a subtle enhancement of luminal epithelial Le $\mathrm{e}^{\mathrm{x}}$ expression by progesterone plus oestrogen was observed in ovariectomized mice (Kimber and Lindenberg, 1990), although Babiarz and Hathaway (1988) reported that glandular Le $\mathrm{e}^{\mathrm{x}}$ expression required both oestrogen and progesterone, while luminal expression required oestrogen alone.

The interactions between oestrogen and progesterone in the uterus are complex and, although the glycosylation machinery is stimulated by oestrogen (Dutt et al,, 1986; Carson et al., 1987,1990 ), the response to oestrogen and progesterone is molecule- and tissue-specific. Tissue variation in hormonal regulation of antigens cannot be accounted for by steroid receptor modulation alone (Wheeler et al., 1987). Differences in steroidal control of various molecules occur between glandular and luminal epithelia (Babiarz and Hathaway, 1988; Svalander et al., 1990; Kimber et al., 1994). Luminal and glandular epithelia also differ in their proliferative response to ovarian steroids (Martin and Finn, 1968; Martin et al., 1973). Our results indicate that, in rats, glandular and luminal expression of a number of carbohydrate antigens are controlled independently. For example, the $\mathrm{A}$ antigen is present from day 3 of pregnancy and is stimulated by progesterone on glands, but it is expressed on the luminal epithelium from day 6 of pregnancy and in refractory ovariectomized animals. The clear distinction between glandular and luminal staining, seen in sections through the glandular-luminal junction, suggests precise control at the level of individual cells. Possibly, shared carbohydrate epitopes on glands and lumen are carried on different molecules. Alternatively, glandular and luminal epithelia may differ in response to ovarian steroids owing to differences in receptors or interaction between ligand-receptor complexes and nuclear genes. However, regulatory molecules such as growth factors may exert disparate influences on these two epithelia. Information is needed on the control of carbohydrate antigens by epidermal growth factor (EGF) family members, particularly heparin binding EGF-like growth factor (HB-EGF; 
Abraham et al., 1993; Das et al., 1994b; Zhang et al., 1994), and their common receptor, implicated in many effects of oestrogen in the uterus (Mukku and Stancel, 1985; Nelson et al., 1991; McLachlan et al., 1991; Ignar-Trowbridge et al., 1992; Das et al., 1994a).

Although a number of endometrial epithelial (glyco)proteins are stimulated by oestrogen (Kuivanen and De Sombre, 1985; LeJeune et al., 1985; Anderson et al., 1986), there are few molecular markers of specific phases in the endometrial cycle. In ovariectomized rats, three endometrial epithelial proteins detected in the pre-receptive period disappeared within $12 \mathrm{~h}$ of injection with nidatory oestrogen (receptive period), but no new proteins could be detected. In the refractory period, a further protein was lost but two proteins reappeared and two appeared for the first time (Mulholland and Leroy, 1989). Two new Ricinus communis agglutin-I/II-reactive glycoproteins reported to be expressed on days 3-4 of pregnancy in mice (Horvat, 1993) may indicate pre-receptive epithelium. Although few proteins specific to the pre-receptive or refractory phases have been identified, and none specific to the receptive period, it is suggested that differentiation of a receptive luminal epithelium is linked with changes in the expression or distribution of cell surface components (Denker, 1990; Glasser and Mulholland, 1993; Kimber et al., 1994). Vital attachment epitopes for the embryo may become exposed apically on the luminal epithelium and anti-adhesive moieties may be removed at this time. These changes are thought to be reversed in the refractory phase, implying the fine modulation of exposed antigens by the masking and unmasking of carbohydrate epitopes. Our study suggests that expression of $\mathrm{A}$ histo-blood group antigen is a constitutive part of these changes and a useful marker of initiation of the refractory period in rats.

In conclusion, there are differences between rats and mice in the carbohydrate epitopes expressed by the endometrial epithelium and in their steroidal control. Histo-blood group A and $B$ antigens, undetectable in the endometria of mice, are present in the rat, while H-type-I, expressed in both species, is stimulated by oestrogen in mice and by progesterone in rats. These differences reflect subtle variations in the control of glycosylation machinery, cell surface molecules and, possibly, implantation mechanisms. Identified stage-specific markers can be used in vivo and in vitro to investigate the response of the endometrial epithelium to regulatory agents. The possible role of these antigens in implantation awaits further investigation.

The authors thank J. Bentley for technical assistance and J. Mulholland and G. Wang for support and helpful suggestions. Funding for different parts of this study has been provided by the MRC UK, the Victoria University of Manchester, UK, BioCarb $A B$ (J. Bentley, S. J. Kimber) and the Birthright Trust UK (I. M. Iilingworth), Texas Advanced Technology Program (494900) and National Institute of Health USA Program HD-257189 (S. R. Glasser) and a Wellcome Trust Travel grant (S. J. Kimber).

\section{References}

Abraham JA, Damm D, Bajordi A, Miller J, Klagsbrun M and Ezekowitz RAB (1993) Heparin binding EGF-like growth factor: characterization of rat and mouse cDNA clones, protein domain conservation across species and transcript expression in tissues Biochemical and Biophysical Research Communication 190 125-133

Anderson TL and Hoffman LH (1984) Alterations in epithelial glycocalyx of rabbit uteri during early pseudopregnancy and pregnancy and following ovariectomy American Journal of Anatomy $171321-334$

Anderson TL, Olson GE and Hoffman LH (1986) Stage-specific alterations in the apical membrane glycoproteins of endometrial epithelial cells related to implantation in rabbits Biology of Reproduction 34 701-720

Babiarz BB and Hathaway HJ (1988) Hormonal control of the expression of antibody-defined lactosaminoglycans in the mouse uterus Biology of Reproduction $39699-706$

Bevilacqua MP and Nelson RM (1993) Selectins Journal of Clinical Investigation 91 379-387

Bouhours D, Larsson J-F, Lundblad A and Hansson G (1987) Developmental changes of blood group A-active glycosphingolipids with type 1 and type 2 chains in rat small intestine Glycoconjugate Journal 4 59-71

Brodin T, Sjogren HO, Lundblad A, Dahmen J, Nilsson B, Messeter L, Martensson $S$, Heldrup J (1987) A monoclonal antibody that recognizes both Le $b$ and $Y$ (Ley) antigens Glycoconjugate Journal 4 399-406

Brodin TN, Dahmen J, Nilsson B, Messeter L, Martensson S, Heldrup J, Sjogren HO, Lundblad A (1988) Monoclonal antibodies produced by immunization with neoglycoproteins containing Gala1-4Gal $\beta 1-4 G l c \beta-0$ and GaloI4 Gal $\beta 1-4$ GlcNAc $\beta-0$ residues: useful immunochemical and cytochemical reagents for blood group $P$ antigens and a differentiation marker in Burkitt lymphoma and other B cell malignancies International Journal of Cancer $\mathbf{4 2}$ 185-194

Brown DG, Warren VN, Pahlsson P and Kimber SJ (1993) Carbohydrate antigen expression in murine embryonic stem cells and embryos. 1 Lacto and neo-lacto determinants Histochemical Journal 25 452-463

Brown EO, Sundstrom SA, Komm BS, Yi Z, Teuscher C and Lyttle CR (1990) Progesterone regulation of estradiol-induced rat uterine secretory protein, Complement C3 Biology of Reproduction $42713-719$

Carson DD, Tang J-P and Hu G (1987) Estrogen influences dolichyl phosphate distribution among glycolipid pools in mouse uteri Biochemistry 26 15981606

Carson DD, Farrar JD, Laidlaw J and Wright DA (1990) Selective activation of the $\mathrm{N}$-glycosylation apparatus in uteri by estrogen Joumal of Biological Chemistry 265 2947-2955

Chavez DJ and Anderson TL (1985) The glycocalyx of the mouse uterine luminal epithelium during estrus; early pregnancy; the peri-implantation period and delayed implantation Biology of Reproduction 32 1135-1142

Chen, HT and Kabat EA (1985) Immunochemical studies on blood groups Joumal of Biological Chemistry $26013208-13217$

Colwell TP (1969) Implantation and development of mouse egg transferred to the uteri of non-progestational mice Journal of Reproduction and Fertility 19 239-242

Das SK, Tsukamura H, Paria BC, Andrews GK and Dey SK (1994a) Differential expression of epidermal growth factor receptor (EGF-R) gene and regulation of EGF-R bioactivity by progesterone and estrogen in the adult mouse uterus Endocrinology 134 971-981

Das SK, Wang X-N, Paria BC, Damm D, Abraham JA, Klagsbrun M, Andrews GK and Dey SK (1994b) Heparin-binding EGF-like growth factor gene is induced in the mouse uterus temporally by the blastocyst solely at the site of its apposition: a possible ligand for interaction with blastocyst EGFreceptor in implantation Development 120 1071-1083

Denker H-W (1990) Trophoblast-endometrial interactions at embryo implantation: a cell biological paradox. In Trophoblast Invasion and Endometrial Receptivity: Trophoblast Research 4 pp 3-29 Eds H-W Denker and JD Aplin. Plenum Medical Book Company, New York

Dutt A, Tang J-P, Welply JK and Carson DD (1986) Regulation of N-linked glycoprotein assembly in uteri by steroid hormones Endocrinology 118 661-673

Enblad P, Glimelias B, Busch C, Pahlman L, Poutin J, Chester MA, Lundblad A (1986) Comparative immunohistochemical demonstration of fucosylated carbohydrate antigens and CEA in adenomas and carcinomas of the rectum and rectosigmoid Anticancer Research 6 139-146

Enders AC and Schlafke S (1974) Surface coats of the mouse blastocyst and uterus during the preimplantation period Anatomical Record 180 137-150

Enders AC, Chavez DJ and Schlafke S (1981) Comparison of implantation in utero and in vitro. In Cellular and Molecular Aspects of Implantation pp 365-382 Eds SR Glasser and DW Bullock. Plenum Press, New York

Fenderson BA, Eddy EM and Hakomori S (1990) Glycoconjugate expression during embryogenesis and its biological significance Bioessays 12 173-179 
Finn CA and Bredl JCS (1973) Studies on the development of the implantation reaction in the mouse uterus: influence of actinomycin $D$ Journal of Reproduction and Fertility 9 301-309

Finn CA and Martin L (1970) The role of the oestrogen secreted before oestrus in the preparation of the uterus for implantation in the mouse Joumal of Endocrinology 47 431-438

Glasser SR (1990) Biochemical and structural changes in uterine endometrial cell types following natural or artificial deciduogenic stimuli. In Trophoblast Invasion and Endometrial Receptivity: Trophoblast Research 4 pp 377-416 Eds H-W Denker and JD Aplin. Plenum Medical Book Company, New York

Glasser SR and McCormack SA (1979a) Functional development of rat trophoblast and decidual cells during establishment of the hemochorial placenta Advances in BioScience 25 165-197

Glasser SR and McCormack SA (1979b) Estrogen modulated uterine gene transcription in relation to decidualization Endocrinology 104 1112-1118

Glasser SR and Mulholland J (1993) Receptivity is a polarity dependent structural function of hormonally regulated uterine epithelial cells Microscopical Research Techniques 25 106-120

Hakomori S-I (1989) Aberrant glycosylation in tumors and tumor-associated antigens Advances in Cancer Research 52 257-331

Hewitt K, Beer AE and Grinnell F (1979) Disappearance of anionic sites from the surface of the rat endometrial epithelium at the time of implantation Biology of Reproduction $21691-707$

Holgersson J, Breimer ME and Samuelsson BO (1992) Basic biochemistry of cell surface carbohydrates and aspects of the tissue distribution of histo-blood group ABH and related glycosphingolipids Acta Pathologica Microbiologica et Immunologica Scandinavica 100 Supplement 27 18-27

Horvat B (1993) Galactose binding lectins as markers of pregnancy-related glycoproteins Histochemistry 99 95-101

Ignar-Trowbridge DM, Nelson KG, Bidwell MC, Curtis SW, Washburn TF, McLachlan JA and Korach KS (1992) Coupling of dual signalling pathways: epidermal growth factor action involves the estrogen receptor Proceedings of the National Academy of Sciences 89 4658-4662

Jansen RPS, Turner M, Johannisson E, Langren BM and Diczfalusy E (1985) Cyclic changes in human endometrial surface glycoproteins: a quantitative histochemical study Fertility and Sterility $\mathbf{4 4} 85-91$

Kimber SJ (1988) The role of fucosylated glycoconjugates in cell-cell interactions of the mammalian pre-implantation embryo. In Eukaryote Cell Recognition: Concepts and Model Systems pp 194-224 Eds GP Chapman, CC Ainsworth and CJ Chatham. Cambridge University Press, Cambridge

Kimber SJ (1994) Carbohydrates as low affinity binding agents involved in initial attachment of the mammalian embryo at implantation. In Early Fetal Growth and Development pp 75-102 Eds RHT Ward, SK Smith and D Donnai. Royal College of Obstetricians and Gynaecologists Press, London

Kimber SJ and Lindenberg S (1990) Hormonal control of carbohydrate determinants involved in implantation Journal of Reproduction and Fertility $\mathbf{8 9}$ 13-21

Kimber S, Lindenberg S and Lundblad A (1988) Distribution of some GalB1$3(4) \mathrm{Gl}$ cNAc related carbohydrate antigens on the mouse uterine epithelium in relation to the peri-implantation period Journal of Reproductive Immunology 12 297-313

Kimber SJ, Waterhouse R and Lindenberg $\mathbf{S}$ (1993) In vitro models for implantation. In Preimplantation Embryo Development pp 244-263 Ed. B Bavister. Springer Verlag, New York

Kimber S, White S, Cook A and Illingworth I (1994) The initiation of implantation. Parallels between attachment of the embryo and neutrophil-endothelial interaction? In Gametes and Embryo Quality pp 171-198 Ed. L Mastrioianni Jr. Parthenon publishers, Carnforth

Kuivanen PC and De Sombre ER (1985) The effects of sequential administration of $17 \beta$-estradiol on the synthesis and secretion of specific proteins in the immature rat uterus Biochemistry 22 439-451

Lasky LA (1992) Selectins: interpreters of cell-specific carbohydrate information during inflammation Science $\mathbf{2 5 8} \mathbf{9 6 4 - 9 6 9}$

Lejeune B, Lecocq R, Lamy R, Deschacht J and Leroy F (1985) Patterns of protein synthesis in endometrial tissue from ovariectomized rats treated with oestradiol and progesterone Journal of Reproduction and Fertility $73 \quad 223-228$

Lindenberg S, Kimber SJ and Kallin E (1990) Carbohydrate binding properties of mouse embryos Journal of Reproduction and Fertility 89 431-439
Lindenberg S, Sundberg K, Kimber SJ and Lundblad A (1988) The milk oligosaccharide, lacto- $N$-fucopentaose I inhibits attachment of mouse blastocysts on endometrial monolayers Joumal of Reproduction and Fertility 83 149-158

McCormack JT and Greenwald GS (1974) Progesterone and estradiol-17 $\beta$ concentrations in the peripheral plasma during pregnancy in the mouse Journal of Endocrinology 62 101-107

McLachlan JA, Nelson KG, Takahashi T, Bossert NL, Newbold RR and Korach KS (1991) Do growth factors mediate estrogen action in the uterus? New Biology of Steroid Hormones Serono Symposium 74 337-344

Martin L and Finn CA (1968) Hormonal regulation of cell division in epithelial and connective tissue of the mouse uterus Journal of Endocrinology 41 363-371

Martin L, Finn CA and Trinder G (1973) Hypertrophy and hyperplasia in the mouse uterus after oestrogen treatment: an autoradiographic study Journal of Endocrinology 56 133-144

Morris JE and Potter SW (1984) A comparison of developmental changes in surface charge in mouse blastocyst and epithelium using DEAE beads and dextran sulphate in vitro Developmental Biology 103 190-199

Mukku VR and Stancel GM (1985) Receptors for epidermal growth factor in the rat uterus Endocrinology 117 149-154

Mulholland J and Glasser SR (1991) Uterine preparation for blastocyst attachment. In Cellular Signals Controlling Uterine Function pp 81-97 Ed. LA Lavia. Plenum Press, New York

Mulholland J and Leroy F (1989) Protein and mRNA synthesis in the periimplantation rat endometrium. In Blastocyst Implantation pp 31-38 Ed. K Yoshinaga Serono Symposium USA. Adams Publishing Group, Boston

Nelson KG, Takahashi T, Bossert NL, Walmer DK and McLachlan JA (1991) Epidermal growth factor replaces estrogen in the stimulation of female genital tract growth and differentiation Proceedings of the National Academy of Sciences USA $\mathbf{8 8} \quad 21-25$

Nelson KG, Takahashi T, Lee D, Luetteke NC, Bossert NL, Ross K, Eitzman BE and McLachlan JA (1992) Transforming growth factor- $\alpha$ is a potent mediator of estrogen action in the mouse uterus Endocrinology 131 1657-1664

Oriol R, Mollicone R, Coullin P, Dalix A-M and Candelier J-J (1992) Genetic regulation of the expression of $\mathrm{ABH}$ and Lewis antigens in tissues Acta Pathologica Microbiologica et Immunologica Scandinavica 100 Supplement 27 $28-38$

Psychoyos A (1973) Hormonal control of ovoimplantation Vitamins and Hormones 31 201-256

Psychoyos A (1986) Uterine receptivity for nidation Annals of the New York Academy of Sciences USA 476 36-42.

Steuden I, Duk M, Czerwinski M, Radzikowska C and Lisowska E (1985) The monoclonal antibody, anti-asialoglycophorin from human erythrocytes, specific for B-D-Gal-D-GalNAc-chains (Thomsen-Friedenreich Receptors) Glycoconjugate Journal 2 203-214

Svalander PC, Odin P, Nilsson BO and Obrink B (1990) Expression of cell CAM-105 in the apical surface of rat uterine epithelium is controlled by ovarian steroid hormones Journal of Reproduction and Fertility 88 213-221

Teng TT, Walker MP, Bhattacharyya SN, Klapper DG, DiAugustine RP and McLachlan JA (1986) Purification and properties of an oestrogen-stimulated mouse uterine glycoprotein (approx $70 \mathrm{kD}$ ) Biochemical Journal 240 413-422

Wassarman PM (1990) Profile of a mammalian sperm receptor Development 108 1-17

Watson J, Anderson FB, Alam M, O'Grady JE and Heald PJ (1975) Plasma hormones and pituitary luteinizing hormone in the rat during the early stages of pregnancy and after post-coital treatment with Tamoxifen (ICI 46,474) Journal of Endocrinology 65 7-17

Wheeler C, Komm BS and Lyttle CR (1987) Estrogen regulation of receptor synthesis in the immature rat uterus: the effects of progesterone on proteins released into the medium during in vitro incubations Endocrinology $\mathbf{1 2 0}$ 919-923

White S and Kimber SJ (1994) Changes in $\alpha(1-2)$ fucosyltransferase activity in the murine endometrial epithelium during the oestrous cycle, early pregnancy and after ovariectomy and hormone replacement Biology of Reproduction 50 73-81

Zhang Z, Funk C, Roy D, Glasser S and Mulholland J (1994) Heparin binding epidermal growth factor-like growth factor is differentially regulated by progesterone and estradiol in rat uterine epithelial and stromal cells Endocrinology 134 1089-1094 